\title{
Factors associated with child health service delivery by female community health volunteers in Nepal: findings from a national survey
}

Hari Krishna Bhattarai ${ }^{1,2^{*}}$ (D) Pratik Khanal ${ }^{3}$, Vishnu Khanal ${ }^{2}$, Kiran Regmi ${ }^{4}$, Narendra Raj Paudel ${ }^{5}$, Liladhar Dhakal ${ }^{1}$ and Samikshya Singh ${ }^{1}$

\begin{abstract}
Background: Nepal has made a significant improvement in child survival in the last few decades and the involvement of female community health volunteers ( $F C H V s$ ) has been crucial in such achievement. While there have been many studies on child health in Nepal however, rarely explored the status and factors associated with the child health service provided by these volunteers. This study aimed to identify the factors associated with the child health service delivery by FCHVs.

Methods: A national survey was conducted in 2014 in Nepal that included 4302 FCHVs using the structured questionnaire across the 13 geopolitical domains of the country. Factors associated with the use of child health services was examined using Chi-square test $\left(X^{2}\right)$ followed by logistic regression.

Results: Overall, $62.6 \%$ of FCHVs provided at least one child health service. Those FCHVs who utilized money from the FCHV fund, conducted health mothers' group meeting, involved in local committees and those who supported antenatal care and outreach clinics related activities had higher odds of providing child health services. Similarly, FCHVs equipped with the stock of Cotrimoxazole tablet, Zinc tablet, Oral Rehydration Salt packets were more likely to provide child health services. The province-wise analysis showed that FCHVs from Province 5 and Sudur Paschim Province were more likely to provide child health services compared to their counterparts from province 1. Technologywise, FCHVs who were using mobile were more likely to provide child health services.

Conclusions: FCHVs are important human resource in providing child health services in Nepal. To improve child health service delivery by FCHVs; availability of key commodities, involvement of FCHVs in regular health mothers' group meeting, use of mobile phone, involvement in other public health programs and social networks, and utilization of the FCHV fund need to be taken into consideration.
\end{abstract}

Keywords: Child health service, Female community health volunteers, Nepal

\footnotetext{
* Correspondence: hkrishnabhattarai@gmail.com

'JSI Research and Training Institute Inc., Kathmandu, Nepal

${ }^{2}$ Nepal Development Society, Bharatpur, Nepal

Full list of author information is available at the end of the article
}

C C The Author(s). 2020 Open Access This article is licensed under a Creative Commons Attribution 4.0 International License, which permits use, sharing, adaptation, distribution and reproduction in any medium or format, as long as you give appropriate credit to the original author(s) and the source, provide a link to the Creative Commons licence, and indicate if changes were made. The images or other third party material in this article are included in the article's Creative Commons licence, unless indicated otherwise in a credit line to the material. If material is not included in the article's Creative Commons licence and your intended use is not permitted by statutory regulation or exceeds the permitted use, you will need to obtain permission directly from the copyright holder. To view a copy of this licence, visit http://creativecommons.org/licenses/by/4.0/ The Creative Commons Public Domain Dedication waiver (http://creativecommons.org/publicdomain/zero/1.0/) applies to the data made available in this article, unless otherwise stated in a credit line to the data. 


\section{Background}

Global under-five deaths have decreased from 12.6 million in 1990 to 5.4 million in 2017 [1]. After Sub-Saharan Africa, South East Asia has the highest burden of under-five deaths. Diarrhoea and pneumonia are still the major killer diseases among the under-5 year children globally and nationally [2, 3]. Acute Respiratory Infection (ARI) and associated fever, dehydration from diarrhoea and malnutrition are the important contributing causes of childhood morbidity and mortality in developing countries. Most child deaths are caused by diseases that are readily preventable or treatable with proven, cost-effective and qualitydelivered interventions [2].

In developing countries, health system suffers from a chronic shortage of human resources. In this context, the mobilization of community health workers or volunteers has been seen as a cost-effective and promising health system intervention [4]. Nepal started the Female Community Health Volunteers (FCHVs) program in 1988. This program was designed to enhance Nepal's primary health care service delivery network, improve community participation, and expand the outreach of health services in doorsteps. The program was established in all 75 districts of the country by 1995 [5].

Nepal initiated community-based diarrhoeal disease control program in 1982 involving local health workers to promote home-based oral rehydration therapy and case management at the health facilities. This intervention, which also involved FCHVs after their introduction in the health system, had an important role in reducing child morbidity and mortality attributed by diarrhoea [6]. In 1997, an evaluation of community-based pneumonia case management supported by the World Health Organization (WHO) further paved the way to involve the FCHVs to treat the pneumonia cases [7]. Given that the percentage of diarrheal cases treated with Oral Rehydration Salt (ORS) and zinc by FCHVs among the total diarrhoeal cases reported throughout the county was $64 \%$ in 2014/15 and 65\% in 2015/16, they are an important cadre to curb child deaths and sickness [3]. Recognizing the importance of community-based interventions, the Government of Nepal initiated community based-integrated management of childhood illness program (CB-IMCI) in 1999 to address major childhood killer diseases (Diarrhoea, ARI, Measles, Malaria and Malnutrition). This intervention involved FCHVs to recognize and treat pneumonia and diarrhoea in children under 5 years of age, and refer the sick neonates and young infants with any danger signs including malnutrition [6].

The role of FCHVs was crucial to achieving Millennium Development Goal 4 targets (reduction of child mortality by two-thirds in 2015 as compared to 1990) in Nepal $[8,9]$ which was also exemplary to the rest of the world. However, evidence regarding the FCHV program in Nepal [10-12] has shown that the FCHV program has been inconsistent in delivering high-quality community health services across the nation. Given their contribution to bridging the gap between health facility and community, it is necessary to motivate and capacitate this workforce for providing community health services including child health. To do so, it is important to understand the factors that are affecting FCHVs performance. However, very few studies have explored the factors affecting their performance. Previous studies done in small settings $[10,11]$ suggest that local leadership, work burden, geographical difficulties, inadequate training, limited monitoring and evaluation and incentive issues affect the service delivery by FCHVs. In 2014, the Ministry of Health conducted a national survey on FCHVs [13] for assessing the performance of the FCHV program. In this context, this study aimed to identify child health services provided by FCHVs and determine the factors associated with it using the data from the national survey. The findings of this study will serve as evidence for the policymakers and program managers to focus on management aspects of FCHVs to improve the child health status of the country.

\section{Methods}

\section{Study design and sampling population}

Data for the study was obtained from a nationally representative FCHV Survey conducted in 2014 [13]. The survey was a cross-sectional study based on cluster design. For the study purpose, the country was divided into 13 domains considering ecological and developmental regions of the country. These 13 domains included 36,050 wards. Wards were the primary sampling unit. In each domain, the sampling frame of wards was created and wards were selected randomly to get sample size per domain. In total 257 urban and 4045 rural wards were selected for the sample. The details of the sampling procedure have been reported in the survey report [10].

The study included 4302 FCHVs. They were interviewed using structured questionnaires which can be accessed in survey report [13]. These questionnaires were finalized based on the feedback received through pretest and experts. Trained enumerators were mobilized with a window-based tablet to collect the data. Information related to service delivery was obtained through review of the FCHV service register. A mobile platform namely "Enketo" linked with SurveyCTO was used to collect and analyze data. Detailed data collection methods have been discussed in the survey report [10].

\section{Variables}

\section{Outcome variable}

The outcome variable in this study was the child health service provided by the FCHVs. It was defined as any 
one of the five services recorded in the service register of the FCHVs. These five services included: distribution of ORS packets to diarrhoea cases, distribution of Zinc tablet to a child suffering from diarrhoea, examine the child for ARI, distribution of cotrimoxazole pediatric tablet to a child suffering from pneumonia, and counselling or referral service to the malnourished child.

\section{Independent variables}

The independent variables included characteristics related to socio-demography, work profile of FCHVs, supports received by FCHVs, governance of the FCHV program, availability of commodities and service delivery by FCHVs.

Socio-demographic variables included the age, caste, educational status, residence and province. In the survey, FCHVs were labelled as "literate" if they had an education level of sixth grade and above, or if those with less than that level of schooling but could fully or partially read a simple sentence written in the card. The work profile of the FCHVs included time taken to reach the health facility, use of mobile phone and years of work experience. The time taken to reach health facility was grouped in three categories (less than $30 \mathrm{~min}, 30-60 \mathrm{~min}$ and more than $1 \mathrm{~h}$ ) and years of work experience was also grouped into three categories (less than 1 year, 1-5 years and more than 5 years). Support received by FCHVs included information about whether they have received basic training (yes/no), dress allowance (yes/ no), incentive received (yes/no) and use of FCHV fund (yes/no). Information on the availability of key commodities included the availability of ORS packets (yes/no) and zinc tablet (yes/no) to treat diarrhoea and Cotrimoxazole tablet (yes/no) to treat pneumonia. Service delivery by the $\mathrm{FCHVs}$ included information on the involvement of FCHVs in antenatal care (ANC) services: counseling to pregnant women, involved in testing pregnancy or providing misoprostol for preventing postpartum haemorrhage in case of home delivery (yes/no), conducted health mothers' group meeting (yes/no), supported in immunization clinics (yes/no) and supported in conduction of Primary Health Care-Out Reach Clinics (PHC-ORC) (yes/no). Governance part of the FCHV program included information about affiliation with FCHVs right based organization (yes/no) and involvement with other local committees (yes/no).

\section{Statistical analyses}

Descriptive analysis was performed and presented as frequencies and percentages. Then, the bivariate analysis (chi-square test) was performed to examine the association between dependent and independent variables. The multi-collinearity analysis was performed and variables which had correlation value less than \pm 0.5 were considered in the regression analysis. Multiple logistic regressions were employed to determine which variables could best explain the child health service delivery by FCHVs. Adjusted Odds Ratios (AOR) were presented with their 95\% confidence intervals (CI) and $p$-value of less than 0.05 was considered as statistical significance. Sampling weight was used to adjust the sampling distribution using "svy" command in Stata 13 (StataCorp LP, College Station, TX, USA) [14].

\section{Ethics}

The ethical approval for this study was obtained from the Nepal Health Research Council (Reference no: 122/ 2014) which is the government body that approves human researches and monitors such studies within the country. Written informed consent was taken from the study participants before the data collection and personal identifiers were removed during the data analysis.

\section{Results}

\section{Services provided by FCHVs}

Overall, $62.6 \%$ of the FCHVs had provided at least one child health service within the last 3 months before the survey. Among the five child health services, $51.6 \%$ of the FCHVs had treated at least one case of diarrhoea with ORS in the last 3 months, which was the highest among all the services provided and $9.3 \%$ had counselled or referred the malnourished child which was the lowest among all the services provided (Table 1).

\section{Relationship of child health service delivery with the socio-demographic profile of FCHVs}

In the bivariate analysis, child health service delivery by FCHVs was associated with their literacy status, ethnic group, residence and province. FCHV's age was not associated with child health service delivery (Table 2).

\section{Relationship of child health service delivery with other background characteristics}

In the bivariate analysis, child health service delivery was associated with the use of mobile phone, time to reach the nearest public health facility, training received, dress

Table 1 Proportion of FCHVs who provided different child health services ( $n=4302)$

\begin{tabular}{ll}
\hline Child health services $^{\mathbf{a}}$ & $\mathbf{N}(\%)$ \\
\hline Diarrhoea treated with ORS & $2220(51.6)$ \\
Diarrhoea treated with Zinc & $1910(44.4)$ \\
Examined for a cough or cold & $1906(44.3)$ \\
Treated with cotrimoxazole for possible pneumonia cases & $1045(24.3)$ \\
Malnourished children counselled or referred & $400(9.3)$ \\
Provided at least one child health-related services & $2693(62.6)$ \\
\hline
\end{tabular}

${ }^{\mathrm{a}}$ Multiple responses 
Table 2 Association between socio-demographic characteristics and delivery of child health services $(n=4302)$

\begin{tabular}{|c|c|c|c|}
\hline $\begin{array}{l}\text { Background } \\
\text { characteristics }\end{array}$ & $\begin{array}{l}\text { Total } \\
\text { n (\%) }\end{array}$ & $\begin{array}{l}\text { Provided child } \\
\text { health services } \\
\%(95 \% \mathrm{Cl})\end{array}$ & $p$ value \\
\hline \multicolumn{4}{|l|}{ Age } \\
\hline$<25 \mathrm{yr}$ & $204(4.38)$ & $58.04(52.11,63.76)$ & \multirow[t]{4}{*}{0.477} \\
\hline $25-39 y r$ & $1735(39.09)$ & $63.24(60.15,66.23)$ & \\
\hline $40-54 \mathrm{yr}$ & $1869(43.62)$ & $62.84(59.43,66.12)$ & \\
\hline $55+y r$ & $494(12.9)$ & $61.79(57.96,65.48)$ & \\
\hline \multicolumn{4}{|l|}{ Literacy } \\
\hline Illiterate & 708 (18.4) & $52.44(47.67,57.16)$ & \multirow[t]{2}{*}{$0.001^{*}$} \\
\hline Literate & 3592 (81.6) & $64.92(62.56,67.22)$ & \\
\hline \multicolumn{4}{|l|}{ Caste } \\
\hline Hill caste & $1812(39.71)$ & $66.95(64.1,69.68)$ & \multirow[t]{5}{*}{$0.008^{*}$} \\
\hline Terai caste & $512(14.08)$ & $58.17(50.12,65.82)$ & \\
\hline Dalits & $260(6.35)$ & $68.19(60.94,74.64)$ & \\
\hline Janajatis & $1628(37.69)$ & $59.49(56.73,62.19)$ & \\
\hline Others & $90(2.17)$ & $51.73(35.72,67.4)$ & \\
\hline \multicolumn{4}{|l|}{ Residence } \\
\hline Urban & $257(0.8)$ & $55.66(51,60.21)$ & \multirow[t]{2}{*}{$0.008^{*}$} \\
\hline Rural & 4045 (99.2) & $62.71(60.26,65.09)$ & \\
\hline \multicolumn{4}{|l|}{ Province } \\
\hline 1 & $825(17.53)$ & $62.36(58.05,66.49)$ & \multirow[t]{7}{*}{$0.001^{*}$} \\
\hline 2 & $521(19.36)$ & $57.35(51.84,62.69)$ & \\
\hline Bagmati & $702(16.76)$ & $57.97(55.19,60.7)$ & \\
\hline Gandaki & $361(12.75)$ & $55.84(50.75,60.81)$ & \\
\hline 5 & $778(14.85)$ & $73.12(70.11,75.93)$ & \\
\hline Karnali & $410(9.13)$ & $59.87(54.63,64.89)$ & \\
\hline Sudurpaschim & 705 (9.63) & $77.48(73.39,81.1)$ & \\
\hline \multicolumn{4}{|c|}{ Years of work experience } \\
\hline$<$ one year & $131(3.04)$ & $51.4(40.86,61.32)$ & \multirow[t]{3}{*}{$<0.05$} \\
\hline $1-5$ year & $733(17.04)$ & $65.24(61.45,68.84)$ & \\
\hline$>5$ years & 3438 (79.92) & $62.56(59.95,65.09)$ & \\
\hline
\end{tabular}

$P$ value: from Chi-square test

allowance received, availability of Zinc, availability of ORS, availability of Cotrimoxazole, support in ANC service, support in PHC-ORC clinic, conduction of health mother's group meeting, use of FCHV fund and involvement in local committees. On the other hand, child health service delivery was not associated with the incentive received, support in immunization clinic and FCHVs' involvement in a right based organization (Table 3).

\section{Factors associated with child health service delivery}

The results of multiple regression analyses are presented in Table 4. The FCHVs from Muslim and other tarai caste were less likely to provide child health services compared to the hill caste FCHVs (AOR $=0.52,95 \% \mathrm{CI}$ : 0.32, 0.84). Likewise, FCHVs from Province 5 (AOR $=$ 1.83, 95\% CI: 1.43, 2.32) and Sudurpaschim province $(\mathrm{AOR}=2.45,95 \% \mathrm{CI}: 1.89,3.17)$ were twice more likely to provide child health services than the FCHVs from Province 1.

Availability of health commodities was associated with the FCHV's service performance. FCHVs having ORS packets $(\mathrm{AOR}=1.44,95 \% \mathrm{CI}: 1.22,1.70)$, Zinc tablets $(\mathrm{AOR}=1.48,95 \% \mathrm{CI}: 1.27,1.72)$ and Cotrimoxazole tablets $(\mathrm{AOR}=1.27,95 \% \mathrm{CI}: 1.09,1.48)$ in stock were more likely to provide child health services. The FCHVs who supported pregnant women in ANC related activities $(\mathrm{AOR}=2.22,95 \% \mathrm{CI}: 1.72,2.87)$, supported PHC-ORC $(\mathrm{AOR}=1.34,95 \% \mathrm{CI}: 1.15,1.55)$ and conducted health mothers' group meeting (AOR $=1.66,95 \% \mathrm{CI}: 1.21,2.2$ ) within the last 3 months had significantly higher odds of providing child health services than those who did not. The FCHVs who utilized money within last 1 year from the $\mathrm{FCHV}$ fund $(\mathrm{AOR}=1.31,95 \% \mathrm{CI}: 1.14,1.51)$ were more likely to provide child health services compared to those who did not use the money from the fund. Similarly, FCHVs who used a mobile phone $(\mathrm{AOR}=1.64$, $95 \%$ CI: $1.35,1.98$ ) had higher odds to provide child health services as compared to those who did not use the mobile phone. Likewise, FCHVs who were involved in different local committees (AOR $=1.29,95 \%$ CI: 1.11 , 1.49). were more likely to provide the child health services than those who were not involved in such committees.

In the adjusted analysis, literacy, residence, time to reach the nearest health facility, training received and dress allowance received were not significantly associated with the child health service delivery provided by FCHVs (Table not shown).

\section{Discussion}

The sharp decline in child mortality in Nepal after the 1980s has been attributed to inexpensive communitybased interventions [7, 15-17] led by local health workers and FCHVs. Studies around the world have shown that community-based interventions with minimal training to community health volunteers and ensuring the availability of life-saving key commodities contributes to the decline in child mortality [18-21]. Our study findings demonstrate that nearly two out of three FCHVs were involved in providing at least one child health service in the last 3 months before the survey. There is no doubt about the importance of FCHVs in rendering child health services. For instance, 67\% of all the diarrhoea cases in the country were reported by FCHVs in fiscal year 2017/18 [22]. However, it is also relevant to understand the reasons for not providing child health services by the remaining FCHVs. This 
Table 3 Association between other background characteristics and child health service delivery $(n=4302)$

\begin{tabular}{llll}
\hline Characteristics & $\begin{array}{l}\text { Total } \\
\mathrm{n}(\%)\end{array}$ & $\begin{array}{l}\text { Provided child } \\
\text { health services\% } \\
(95 \% \mathrm{Cl})\end{array}$ & $p$ value \\
& & & \\
\hline
\end{tabular}

\begin{tabular}{l}
\hline Use of mobile phone \\
$\begin{array}{llll} & & & \\
\text { No } & 727(17.38) & 49.30(43.34,55.27) & <0.001^{*} \\
\text { Yes } & 3575(82.62) & 65.46(63.31,67.54) & \end{array}$
\end{tabular}

Time to reach the nearest public health facility

$\begin{array}{llll}<30 \mathrm{~min} & 1462(34.36) & 59.84(56.25,63.32) & 0.018^{*} \\ 30-60 \mathrm{~min} & 1645(38.1) & 64.90(61.77,67.9) & \\ >60 \mathrm{~min} & 1195(27.54) & 63.05(60.81,65.24) & \end{array}$

Received basic training

$\begin{array}{lccc}\text { No } & 195(3.79) & 54.09(47.99,60.07) & 0.009^{*} \\ \text { Yes } & 4107(96.21) & 62.99(60.42,65.48) & \\ \text { Received dress allowance } & & \\ \text { No } & 193(4.5) & 52.61(46.39,58.76) & 0.008^{*} \\ \text { Yes } & 4109(95.5) & 63.12(60.45,65.71) & \end{array}$

Received monetary/ non-monetary incentive other than dress allowance

$\begin{array}{llll}\text { No } & 2735(64.18) & 61.5(58.24,64.66) & 0.068 \\ \text { Yes } & 1567(35.82) & 64.71(62.37,66.97) & \\ \text { ORS in stock } & & & \\ \text { No } & 986(24.69) & 52.15(47.52,56.74) & <0.001^{*} \\ \text { Yes } & 3315(75.31) & 66.1(63.9,68.24) & \end{array}$

Zinc in stock

$\begin{array}{llll}\text { No } & 1993(46.62) & 54.93(52.44,57.4) & <0.001^{*} \\ \text { Yes } & 2308(53.38) & 69.41(66.74,71.95) & \end{array}$

Cotrimoxazole pediatric in stock

$\begin{array}{llll}\text { No } & 2224(51.47) & 56.2(53.59,58.78) & <0.001^{*} \\ \text { Yes } & 2077(48.53) & 69.5(66.7,72.16) & \end{array}$

Supported in ANC services in the last 3 months

$\begin{array}{llll}\text { No } & 346(8.65) & 39.02(32.43,46.03) & <0.001^{*} \\ \text { Yes } & 3956(91.35) & 64.89(62.23,67.45)\end{array}$

Provided support in PHC-ORC in the last 3 months

$\begin{array}{llll}\text { No } & 2260(51.58) & 58.07(55.43,60.66) & <0.001^{*} \\ \text { Yes } & 2042(48.42) & 67.53(65.19,69.78) & \end{array}$

Supported in immunization clinic in the last 3 months

$\begin{array}{llll}\text { No } & 1753(40.25) & 58.34(55.96,60.68) & 0.913 \\ \text { Yes } & 2549(59.75) & 65.55(62.76,68.25) & \end{array}$

Conducted health mother's group meetings in the last 3 months

No $239(4.74) \quad 37.93(30.79,45.64)<0.001^{*}$

Used FCHV fund

$\begin{array}{llll}\text { No } & 1743(39.96) & 58.22(54.64,61.71) & <0.001^{*} \\ \text { Yes } & 2399(60.04) & 66.38(63.7,68.97)\end{array}$

Table 3 Association between other background characteristics and child health service delivery $(n=4302)$ (Continued)

\begin{tabular}{|c|c|c|c|}
\hline Characteristics & $\begin{array}{l}\text { Total } \\
\text { n (\%) }\end{array}$ & $\begin{array}{l}\text { Provided child } \\
\text { health services\% } \\
(95 \% \mathrm{Cl})\end{array}$ & $p$ value \\
\hline \multicolumn{4}{|c|}{ Involved in local committees } \\
\hline No & $1596(38.68)$ & $57.26(53.91,60.54)$ & \multirow[t]{2}{*}{$<0.001^{*}$} \\
\hline Yes & $2706(61.32)$ & $66.05(63.85,68.18)$ & \\
\hline \multicolumn{4}{|c|}{ Associated with FCHVs right based organization } \\
\hline No & $3821(89.98)$ & $61.6(58.92,64.2)$ & \multirow[t]{2}{*}{0.491} \\
\hline Yes & $481(10.02)$ & $72.1266 .62,77.02)$ & \\
\hline
\end{tabular}

might be related to motivational factors as well as supply-side factors, partly explained by our study findings, but need further exploration.

In our study, availability of key commodities (Cotrimoxazole tablet, Zinc tablet and ORS) with FCHVs was significantly associated with providing child health services. The limited availability of commodities severely restricts FCHVs' ability to provide services and affects the community trust on them. The major reason for this is due to the inadequate stock of drugs in health facilities [23] which is again the consequence of procurement and transportation hurdles. Reducing commodity stock-out rates across health facilities in Nepal and equipping FCHVs with these commodities could thus reasonably be assumed to contribute to improved service delivery and child health outcomes. Though the importance of local health workers cannot be ignored, mobilization of FCHVs has supported in bringing services closer to the community in a country which has been suffering from a chronic shortage of human resources for health. A study from Nepal [12] has indicated that women did not prefer to contact FCHVs during the illness of their child because of their incompetency and lack of medicines. Thus, for an effective FCHV program, their mobilization needs to be continuously monitored and supervised by local health workers with regular competency-based training and sufficient supply of logistics.

The Government of Nepal has created an FCHV funda micro-credit fund, which is managed by FCHVs. They use this fund in income-generating activities. Our study revealed that the utilization of money from the fund was positively associated with child health service delivery by FCHVs. The fund might have strengthened their economic status, increased the sense of belongingness and improved their performance which is also supported by a qualitative study done in Nepal [10].

The FCHVs who supported PHC-ORC and ANC related activities were more likely to provide child health services as compared to those who did not support these activities. In these activities, the FCHVs are involved in educating and counseling couples on family planning; 
Table 4 Determinants of child health service delivery by FCHVs

\begin{tabular}{|c|c|}
\hline Characteristics & Adjusted Odds Ratio (95\% CI) \\
\hline \multicolumn{2}{|l|}{ Caste } \\
\hline Hill caste & Ref \\
\hline Terai caste & $0.92(0.70,1.22)$ \\
\hline Dalits & $1.28(0.93,1.77)$ \\
\hline Janajatis & $0.92(0.78,1.09)$ \\
\hline Muslim and tarai others & $0.52(0.32,0.84)^{* *}$ \\
\hline \multicolumn{2}{|l|}{ Province } \\
\hline 1 & Ref \\
\hline 2 & $1.27(0.95,1.69)$ \\
\hline Bagmati & $0.94(0.75,1.18)$ \\
\hline Gandaki & $0.93(0.70,1.22)$ \\
\hline 5 & $1.83(1.43,2.32)^{* *}$ \\
\hline Karnali & $0.90(0.68,1.19)$ \\
\hline Sudurpaschim & $2.45(1.89,3.17)^{* *}$ \\
\hline \multicolumn{2}{|l|}{ ORS in stock } \\
\hline No & Ref \\
\hline Yes & $1.44(1.22,1.70)^{* *}$ \\
\hline \multicolumn{2}{|l|}{ Zinc in stock } \\
\hline No & Ref \\
\hline Yes & $1.48(1.27,1.72)^{* *}$ \\
\hline \multicolumn{2}{|c|}{ Cotrimoxazole Pediatric tablet in stock } \\
\hline No & Ref \\
\hline Yes & $1.27(1.09,1.48)^{*}$ \\
\hline \multicolumn{2}{|c|}{ Provided support in the ANC clinics in last 3 months } \\
\hline No & Ref \\
\hline Yes & $2.22(1.72,2.87)^{* *}$ \\
\hline \multicolumn{2}{|c|}{ Provided support in PHC-ORC in the last 3 months } \\
\hline No & Ref \\
\hline Yes & $1.34(1.15,1.55)^{* *}$ \\
\hline \multicolumn{2}{|c|}{ Involved in mother's group meeting } \\
\hline No & Ref \\
\hline Yes & $1.66(1.21,2.27)^{* *}$ \\
\hline \multicolumn{2}{|l|}{ Used FCHV fund } \\
\hline No & Ref \\
\hline Yes & $1.31(1.14,1.51)^{* *}$ \\
\hline \multicolumn{2}{|l|}{ Use of mobile phone } \\
\hline No & Ref \\
\hline Yes & $1.64(1.35,1.98)^{* *}$ \\
\hline \multicolumn{2}{|c|}{ Involved in local committees } \\
\hline No & Ref \\
\hline Yes & $1.29(1.11,1.49)^{* *}$ \\
\hline
\end{tabular}

${ }^{* *}=p<0.01,{ }^{*}=p<0.05 ;$ Adjusted full model distributing commodities; promotingANC, institutional delivery, and postnatal care for mother and newborn [22]. Involving FCHVs in these wide ranges of interventions would aid in the integration of maternal, child and newborn services thus leading to the continuum of care and better outcomes in child survival [21, 24]. It is however equally important to consider the work burden of FCHVs while task shifting and also capacitate FCHVs to deal with cultural and religious issues that surround during pregnancy and childbirth in Nepal as identified in other studies [25, 26].

Our study showed that the participation of FCHVs in health mother's group meeting was associated with the delivery of child health services. These meetings are unique platforms to discuss different health issues and are attended by local women. Studies from Nepal have shown that frequent interactions between mothers and FCHVs were related to the use of child health services from FCHVs [12] and reduction in underweight and stunting status among children [27]. Similarly, a study from Makwanpur, Nepal [28] and Jharkhand and Orissa of India [29] had shown that participatory intervention involving women's group can decrease both maternal and neonatal mortality and improve service utilization.

Our study findings showed that the use of the mobile phone by FCHVs was associated with child health service delivery indicating that a mobile phone could play a potential role to improve child health outcomes. The use of mobile phone and wireless technology has a huge potential to improve the health and wellbeing of the resource constraint communities through communication and exchange of skills among health workers and with communities $[30,31]$. The use of the mobile application to improve maternal and neonatal health outcomes has been studied among FCHVs in Baglung and Dhanusha districts of Nepal which also has shown promising results [32-34]. This might be because FCHVs are likely to be contacted through mobile phone in case of emergency or other health needs by the communities leading to increased service utilization of child health services [33].

Our study findings demonstrated that FCHVs who were involved in the local level committees were more likely to provide child health services than those who were not involved in similar committees. RB Khatri, SR Mishra and V Khanal [35] however are of the view that the involvement of FCHVs in other non-health programs such as forest user groups, community development groups, education, and microcredit and saving groups could compromise their working hours in the health sector leading to poor performance. We put forward that such involvement may open opportunities for social networking leading to higher self-esteem and 
increased performance. However, monitoring of the activities of FCHVs needs to be done by health facilities and local governments for effective performance management of these cadres.

Our study findings indicate that incentives do not affect the delivery of child health services by FCHVs. This might be because of their volunteering role and that FCHVs are motivated by social recognition which is also supported by a qualitative study done in Nepal [36]. Studies have however shown that the issue of fair compensation for FCHVs needs to be addressed [10, 36, 37] as economic insecurity is a strong barrier to volunteering. Motivational activities like the provision of training and dress allowance for FCHVs were not significantly associated with the delivery of child health services in this study. The reason might be that FCHVs had joined volunteerism with the least expectation. In our study, education of FCHVs was not significantly associated with the child health service delivery. This finding contrasts with a study from Dhanusha, Nepal [38] where the educational status of FCHVs was associated with their knowledge and performance on maternal and child health services.

Nepal is in the early stage of implementation of federalism and the constitution has identified health as a fundamental right. While the federal government is responsible for overseeing broader policy, the province and local governments are responsible for the management of the health services $[39,40]$. In the changed federal governance, the task of managing FCHVs comes under the direct responsibility of the local level governments (municipality, rural municipality) who were previously managed by local health posts and primary health centres. The role of local-level governments would thus be crucial to motivate these cadres for contributing to the health of the communities. The FCHVs are complimentary cadres to improve the health of the communities and their effort alone might not be sufficient. It is also necessary that there is increased community demand for health care and the availability of quality health services at health institutions.

This study is based on a large sample size and the findings can be generalizable to the entire country. However, there are inherent limitations to the study. Firstly, its cross-sectional study design does not allow establishing causation. Secondly, this study only focuses on the FCHV's perspective and thus there is an indication of further research to understand the community and service provider's side perspectives. Furthermore, this study doesn't identify the main reasons for not providing or providing child health services. Future research may be needed to explore these factors in detail. Despite these limitations, this study provides useful evidence for the policymakers and program managers for understanding the factors influencing the performance of FCHVs in providing child health services. The evidence can be utilized for efficient and effective utilization of these cadres for improved child survival.

\section{Conclusions}

This study revealed that availability of the essential commodities (Cotrimoxazole tablet, Zinc tablet and ORS), use of mobile phone, conduction of health mothers' group meeting, involvement in local level committees and support in other health programs and utilization of FCHV fund were the determinants of child health service delivery by FCHVs in Nepal. Ensuring a sustainable means to supply these essential commodities and encouraging the involvement of FCHVs in communitybased health services through adequate support system will help to improve child health status in Nepal. The existing FCHV program can benefit from this evidence by motivating these cadres for strengthening child health services at the community level.

\section{Abbreviations \\ AOR: Adjusted Odds Ratio; ARI: Acute Respiratory Infection; CB- \\ IMCl: Community Based Management of Childhood Illness; Cl: Confidence Interval; FCHVs: Female Community Health Volunteers; ORS: Oral Rehydration Salt; PHC-ORC: Primary Health Care Out Reach Clinic; WHO: World Health Organization}

\section{Acknowledgements}

The authors would like to acknowledge the study participants and the field research team.

\section{Authors' contributions}

HKB and LD conceptualized the study and monitored the survey. HKB, LD and SS performed data analysis. KR was the principal investigator of the survey and supported to write the discussion. VK and PK interpreted the results and wrote the discussion section. NRP supervised the study. All authors reviewed the final draft of the manuscript.

\section{Funding}

The national FCHV survey 2014 was funded by USAID, UNICEF and Save the Children.

\section{Availability of data and materials}

Availability of the data is available upon request to the corresponding author.

\section{Ethics approval and consent to participate}

The ethical approval for this study was obtained from the Nepal Health Research Council (Reference no: 122/2014) which is the national peak body that approves human researches and monitors such studies within the country. Written informed consent was taken from the study participants before the data collection and personal identifiers were removed during the data analysis.

\section{Consent for publication}

Not applicable.

\section{Competing interests}

The authors declare that they have no competing interests.

\section{Author details}

${ }^{1}$ JSI Research and Training Institute Inc., Kathmandu, Nepal. ${ }^{2} \mathrm{Nepal}$ Development Society, Bharatpur, Nepal. ${ }^{3}$ Institute of Medicine, Tribhuvan University, Kathmandu, Nepal. ${ }^{4}$ Former Secretary of the Ministry of Health 
and Population, Principal Investigator of the FCHV survey 2014, Kathmandu, Nepal. ${ }^{5}$ Tribhuvan University, Kathmandu, Nepal.

\section{Received: 18 July 2019 Accepted: 11 June 2020} Published online: 19 June 2020

\section{References}

1. UNICEF. Levels \& Trends in child mortality report 2018. In. UNICEF: USA; 2018

2. UNICEF. Levels \& Trends in Child Mortality. In: United Nations Children's Fund; 2015.

3. DoHS: Annual Report 2014/2015. In Department of Health Services; 2015.

4. McCord GC, Liu A, Singh P. Deployment of community health workers across rural sub-Saharan Africa: financial considerations and operational assumptions. Bull World Health Org. 2013;91:244-253b.

5. Ministry of Health. National Female Community Health Volunteer Program Strategy: Ministry of Health, Family Health Division; 2010.

6. Nepal Family Health Program II. Overview of Community-Based Integrated Management of Childhood Illnesses. 2012. http://nfhp.jsi.com/Res/Docs/TB3CBIMCI-O.pdf.

7. Ghimire M, Pradhan YV, Maskey MK. Community-based interventions for diarrhoeal diseases and acute respiratory infections in Nepal. Bulletin of the World Health Organization; 2009.

8. Malla D, Giri K, Karki C, Chaudhary P. Achieving millennium development goals 4 and 5 in Nepal. Int J Obstet Gynaecol. 2011;118.

9. UNICEF: The state of world's children 2009. In United Nations Children's Fund 2008.

10. Schwarz D, Sharma R, Bashyal C, Schwarz R, Baruwal A, Karelas G, Basnet B, Khadka N, Brady J, Silver Z, et al. Strengthening Nepal's Female Community Health Volunteer network: a qualitative study of experiences at two years. BMC Health Serv Res. 2014;14(473). https://doi.org/10.1186/1472-6963-14-473.

11. Panday $S$, Bissell $P, E v T$, Simkhada P. The contribution of female community health volunteers (FCHVs) to maternity care in Nepal: a qualitative study. BMC Health Serv Res. 2017:17(623).

12. Miyaguchi M, Yasuoka J, Poudyal AK, Silwal RC, Jimba M. Female community health volunteers service utilization for childhood illnessimproving quality of health services only is not enough: a cross-sectional study in mid-western region, Nepal. BMC Health Serv Res. 2014;14(1):383.

13. Ministry of Health FHD: Female Community Health Volunteer National Survey Report 2014. Family Health Division, Department of Health Services, Ministry of Health and Population, Kathmandu, Nepal. In. Ministry of Health.; 2015.

14. Pitblado J. Survey data analysis in Stata. In: Canadian Stata Users Group Meeting, vol. 2009; 2009.

15. Pandey MR, Daulaire N, Starbuck E, Houston R, McPherson K. Reduction in total under-five mortality in western Nepal through community-based antimicrobial treatment of pneumonia. Lancet. 1991;338(8773):993-7.

16. Nonyane BA, Kc A, Callaghan-Koru JA, Guenther T, Sitrin D, Syed U, Pradhan Y, Khadka N, Shah R, Baqui AH. Equity improvements in maternal and newborn care indicators: results from the Bardiya district of Nepal. Health Policy Plan. 2015;31(4):405-14.

17. Neupane D, Dawson P, Houston R, Dhakal L, Sharma J, Gargi K, Lagos C, Khanal V, Mishra SR, Kallestrup P. Lower mortality is observed among low birth weight young infants who have received home-based care by female community health volunteers in rural Nepal. BMC Pregnancy Childbirth. 2017;17(1):218

18. Lassi ZS, Haider BA, Bhutta ZA. Community-based intervention packages for reducing maternal and neonatal morbidity and mortality and improving neonatal outcomes. Cochrane Database Syst Rev. 2010;11:11.

19. Christopher JB, Le May A, Lewin S, Ross DA. Thirty years after Alma-Ata: a systematic review of the impact of community health workers delivering curative interventions against malaria, pneumonia and diarrhoea on child mortality and morbidity in sub-Saharan Africa. Hum Resour Health. 2011; 9(1):27.

20. Perry H, Zulliger R. How effective are community health workers. In: An overview of current evidence with recommendations for strengthening community health worker programs to accelerate progress in achieving the health-related Millennium Development Goals Baltimore: Johns Hopkins Bloomberg School of Public Health; 2012.

21. Bhutta ZA, Black RE. Global maternal, newborn, and child health-so near and yet so far. N Engl J Med. 2013;369(23):2226-35.

22. Department of Health Service: Annual Report 2017/18. In Kathmandu: Ministry of Health and Population; 2018.
23. Shakya H, Adhikari S, Gurung G, Pant S, Aryal S, Singh A, Sherpa M. Strengthening national health systems for improving efficiency of health service delivery in Nepal. J Nepal Health Res Counc. 2012;10:101.

24. Jones G, Steketee RW, Black RE, Bhutta ZA, Morris SS, Group BCSS. How many child deaths can we prevent this year? Lancet. 2003;362(9377):65-71.

25. Shah R, Rehfuess EA, Paudel D, Maskey MK, Delius M. Barriers and facilitators to institutional delivery in rural areas of Chitwan district, Nepal: a qualitative study. Reprod Health. 2018;15(1):110.

26. Paudel M, Javanparast S, Dasvarma G, Newman L. A qualitative study about the gendered experiences of motherhood and perinatal mortality in mountain villages of Nepal: implications for improving perinatal survival. BMC Pregnancy Childbirth. 2018;18(1):163

27. Locks LM, Dahal P, Pokharel R, Joshi N, Paudyal N, Whitehead RD Jr, Chitekwe S, Mei Z, Lamichhane B, Garg A. Changes in growth, anaemia, and iron deficiency among children aged 6-23 months in two districts in Nepal that were part of the post-pilot scale-up of an integrated infant and young child feeding and micronutrient powder intervention. Matern Child Nutr. 2018:e12693.

28. Manandhar DS, Osrin D, Shrestha BP, Mesko N, Morrison J, Tumbahangphe KM, Tamang S, Thapa S, Shrestha D, Thapa B. Effect of a participatory intervention with women's groups on birth outcomes in Nepal: clusterrandomised controlled trial. Lancet. 2004;364(9438):970-9.

29. Tripathy P, Nair N, Barnett S, Mahapatra R, Borghi J, Rath S, Rath S, Gope R, Mahto D, Sinha R. Effect of a participatory intervention with women's groups on birth outcomes and maternal depression in Jharkhand and Orissa, India: a cluster-randomised controlled trial. Lancet. 2010;375(9721): 1182-92.

30. WHO: mHealth: New horizons for health through mobile technologies: second global survey on eHealth. In. World Health Organization; 2011.

31. Morrison J, Shrestha NR, Hayes B, Zimmerman M. Mobile Phone Support for Rural Health Workers in Nepal through 'Celemedicine'. J Nepal Med Assoc. 2013;52:538.

32. Sharma R, Harsha A, Acharya P, Okada E, Yangdol T, Bhatta S, Dahal S. Pilot and evaluation of the feasibility SafeSIM: a mobile technology platform for maternal health care coordination in Nepal. Publication Timeline; 2015.

33. Singh JK, Kadel R, Acharya D, Lombard D, Khanal S. Singh SP: 'MATRISUMAN'a capacity building and text messaging intervention to enhance maternal and child health service utilization among pregnant women from rural Nepal: study protocol for a cluster randomised controlled trial. BMC Health Serv Res. 2018;18(1):447.

34. Acharya D, Singh JK, Kadel R, Yoo S-J, Park J-H, Lee K. Maternal factors and utilization of the antenatal care services during pregnancy associated with low birth weight in rural Nepal: analyses of the antenatal care and birth weight records of the MATRI-SUMAN trial. Int J Environ Res Public Health. 2018;15(11):2450.

35. Khatri RB, Mishra SR, Khanal V. Female Community Health Volunteers in Community-Based Health Programs of Nepal: Future Perspective. Front Public Health. 2017:5:181.

36. Glenton C, Scheel IB, Pradhan S, Lewin S, Hodgins S, Shrestha V. The female community health volunteer programme in Nepal: decision makers' perceptions of volunteerism, payment and other incentives. Soc Sci Med. 2010;70(12):1920-7.

37. Baskota S, Kamaraj R. Female community health volunteers program in Nepal: perceptions, Attitudes and Experiences on Volunteerism among Female Community Health Volunteers. Int J Interdisciplinary Multidisciplinary Stud. 2014;1(5):9-15.

38. Acharya D, Singh JK, Adhikari S, Jain V. Association between sociodemographic characteristics of female community health volunteers and their knowledge and performance on maternal and child health services in rural Nepal. J Multidiscip Healthc. 2016;9:111.

39. Government of Nepal. The Constitution of Nepal. In: Government of Nepal, Nepal Law Commission; 2015.

40. Thapa R, Bam K, Tiwari P, Sinha TK, Dahal S. Implementing federalism in the health system of Nepal: opportunities and challenges. Int J Health Policy Manag. 2018

\section{Publisher's Note}

Springer Nature remains neutral with regard to jurisdictional claims in published maps and institutional affiliations. 